\title{
A proximidade pesquisador/objeto como potência criativa: percursos investigativos entre as cenas musicais de Porto Alegre e Montevidéu
}

\author{
The researcher/object proximity as a creative \\ power: \\ investigative paths between the musical scenes of \\ Porto Alegre and Montevideo
}

\section{Felipe Gue Martini}

Doutorando em Comunicação Unisinos/RS. Coordenador do Centro Integrado de Comunicação e do bacharelado em Jornalismo da Faculdade da Serra Gaúcha (FSG/RS). Jornalismo, pesquisador do grupo Processocom e Rede Amlat. Email: guemartini@gmail.com

\section{RESUMO}

A reflexão sobre a proximidade do pesquisador com seu objeto empírico de pesquisa, no caso as cenas musicais do rock independente de Porto Alegre e Montevidéu, surge a partir da noção de psicanálise do conhecimento objetivo, de Gaston Bachelard. Através de questionamentos teóricos críticos, o autor propõe a apreensão poética das realidades objetivas da pesquisa, onde a musicalidade é percebida como potencial metodológico no universo da observação participante.

Palavras-chave: epistemologia; poética; rock.

\section{ABSTRACT}

The reflection about the proximity of the researcher with its empirical object of research, in this case the indie rock music scenes from Porto Alegre and Montevideo, arises from the notion of psychoanalytic of the objective knowledge, by Gaston Bachelard. Through critical theoretical questions, the author proposes the poetic apprehension of objective realities of the research, where music is perceived as a methodological potential in a participant observation universe. Keywords: epistemology; poetic; rock. 


\section{Introduç̃̃o}

Este texto traz uma breve reflexão sobre arte e ciência, sob o ponto de vista da epistemologia crítica e das estéticas da comunicação. É referente à pesquisa "Cenas e materialidades musicais lo-fi entre Porto Alegre e Montevidéu”, em realização no nível de doutorado do Programa de Pós-Graduação da Unisinos. O objetivo da investigação é mapear ressignificações de produtos e cenas musicais reinscritos na atualidade a partir de materialidades e lógicas comunicacionais em uma observação participante com eixo nos produtos de expressividade minoritária, vinculados ao rock independente'.

A minha inserção como músico neste universo permeia a discussão subsequente, onde questiono o olhar poético, a sensibilidade artística e os processos de construção do problema de pesquisa com base nesta "forma" de subjetividade, arranjo particular de apreensão da realidade, escondida entre os novos delírios de pesquisador e sua psicanálise. Tudo começa com a leitura de uma teorização sobre o autêntico, fato que ativa uma memória afetiva vivaz sobre como consumi o rock, boa parte norteamericano, em meados dos anos 1990. Essa chave me conduz a questionar tal teoria (sua leitura atual) e a forma como tenho reconstruído minha experiência de vida do tempo adolescente. É um exercício de psicanálise do conhecimento objetivo (BACHELARD, 1971) onde trato de reposicionar este eu pesquisador no seu fazer científico.

\section{Autenticidade, rock e juventude}

No texto "Reconsiderar el rock", Keir Keightley (2006) aborda algumas transformações do rock em perspectiva histórica e narra o contexto cultural do gênero como um campo autorreflexivo que se apresenta, ao longo das últimas décadas, através de reiteradas recriações inventivas. De início, o próprio surgimento do gênero teria relação com sua diferença qualitativa em relação à música popular, como uma manifestação mais autêntica (embora paradoxalmente transformada numa das primeiras experiências culturais de massa). A autenticidade estaria na gênese rock. não em termos artísticos e estéticos, mas enquanto um discurso de "autêntico" que permeou e permeia suas atualizações, das categorias ligadas ao blues e ao folk, dos anos 1950, até as esquizofrenias do eletrônico e lo-fi, dos anos 2000.

Para Keightley, essa espécie de dimensão discursiva aparece inicialmente no pósguerra, quando o rock'n'roll se apresenta como a música jovem, ligada aos baby boomers, distinta da música adulta, séria, a mais popular nas rádios e paradas até então. A característica marginal surge quase como um diferencial competitivo, a pedra de toque a fabricar novos mercados, impulsionada pelo cinema norte-americano em expansão global. 
El rock surgió porque un segmento del torrente masivo de la música popular fue asociado con una anomalía demográfica concreta: un notable incremento de la población joven en los anos que siguieron a la Segunda Guerra Mundial. Paradójicamente, los números del baby boom magnificaron - en lugar de "masificar" la cultura juvenil. La visión de la juventud como un segmento subordinado y marginal permitió que esta nueva cultura dominante siguiera imaginándose como subcultural (KEIGHTLEY, 2006, p.191).

Estas operações mercadológicas complexas não seguiram modelos rígidos, "a dialética padronização-individuação tende frequentemente a se amortecer em uma espécie de termo médio” (MORIN, 2011, p.22) que não se alcança automaticamente com a execução de fórmulas simplificadas de arte reprodutível. O surgimento ou fabricação do consumidor de rock (como homem médio dos anos 1950-60) tem relação direta com a infantilização dos adultos e a transformação dos adolescentes em consumidores preferenciais. Neste universo, desvelar o autêntico passa por uma engenharia muito complexa estabelecida na contradição entre "a lógica industrial-burocrático-monopolístico-centralizador-padronizadora e a contralógica individualista-inventivo-concorrencial-autonomista-inovadora" (MORIN, 2011, p.18). O potencial aglutinador do rock enquanto gênero musical deve ser discutido caso a caso, numa perspectiva cultural, quando o interesse é fugir do reducionismo habitual de posicioná-lo no centro da cultura massificadora e imperialista do norte contra o sul indefeso.

Em certa medida, o modelo nascente da indústria cultural sobreviveu da diversidade e potencializou o singular em artigo de consumo massivo. É aí que a máquina trituradora do rock passa a transubstanciar uma série de elementos musicais exógenos, o folk e sua postura anticapitalista rural, colocando-se em diferença ao urbano capitalista pós-guerra; posteriormente virá o hard rock como música séria, distinta do rock and roll inocente, destacando-se da postura jovial e reafirmando sua condição de música adulta, nos anos 1970, em seguida o punk como reação ao virtuosismo e a complexidade, afirmando o simples como autêntico e revivendo o anarquismo e o anticonsumo; e assim sucessivamente, com o pós-punk, o glam rock, o indie, o lo-fi, entre tantos outros.

À primeira vista, me identifico com a afirmação de Keightley. Além de pesquisador sou músico, e hoje elaboro elementos de minha memória através de uma racionalidade aplicada a ciência. Minha experiência empírica induz a acreditar neste traço de caráter do rock, que vivenciei como uma epistemologia (do senso comum, citando Boaventura de Sousa Santos) ao longo de um período significativo de minha vida, entre 14 e 28 anos de idade (a questão aqui é se ainda a pratico e de que formas). E não estava só, pois constitui uma carreira musical sólida ${ }^{2}$ em torno da noção não racionalizada de autenticidade, uma sociologia espontânea (BOURDIEU, 2004) nascida da experiência de ser jovem, dispor de tempo livre e aspirar a transformação da sociedade. Parte dessa autenticidade corrompida (seria falsa?) é a afirmação do autodidatismo e do abandono apriorístico das regras e notações musicais. O rock (e 
não só ele) surgiu como uma licença poética na vida de muitos jovens, um lugar onde poderiam exercer a expressão "livre", pois esta polêmica interna da autenticidade (como ser autêntico? o que é ser autêntico? ) se traduziu num lócus gerador de rupturas com sua própria tradição e lugar.

Esse comportamento tem relação com a história de afirmação da cultura rock nas sociedades de diferentes países afastados de seus centros irradiadores (Estados Unidos e Reino Unido), onde constituiu um elo marcante com a cultura adolescentejuvenil em gestação no início dos anos 1950, aliada aos movimentos de dissidência, revolta e recusa da sociedade de consumo, os beatniks e os hippies, por exemplo. $\mathrm{O}$ modelo jovem (que surge como categoria sociológica) compartilhado ao redor do mundo a partir do cinema, da música, dos meios de comunicação de massa traz consigo uma ambivalência geradora que "conduz, por um lado, ao consumo 'estético-lúdico' e à fruição individualista da civilização burguesa; mas [que] contém, ao mesmo tempo, os 'fermentos de uma não-adesão a este mundo adulto que traem o tédio burocrático, a repetição, a mentira e a morte” (MORIN, 2009, p.133). Há muita inspiração nos movimentos libertários, nas vanguardas artísticas, no existencialismo do pós-guerra, mas "pode-se dizer esquematicamente que esta cultura é criada pela adolescência, mas que ela é produzida pelo sistema” (Ibid., p.140, grifo do autor). Apesar disso, é um espaço possível de crítica sociocultural.

Finalmente, el desarrollo por parte del rock de una cultura "anti-masas" en gran escala es probablemente el primer y más influyente ejemplo de una tendencia de alcance más amplio. [...] Antes del nacimiento del rock, las culturas baja y elevada, las tendencias masivas y las marginales, constituían entes claramente diferenciados. Una vez que el rock consiguió romper el vínculo simbólico entre la cultura de masas y el conformismo inconsciente, fue posible establecer nuevas distinciones en el terreno de lo popular, expresar sensibilidades de oposición a través de una cultura de masas comercial y vehiculada por los medios de comunicación (KEIGHTLEY, 2006, p.192).

Portanto, não se trata da defesa utópica da forma como o gênero estabelece sua hegemonia entre públicos diversos, ao favorecer, inclusive, as condições para a infantilização ou o estado de latência da juventude e da rebeldia para consumo cotidiano; minha tentativa é entender como a dupla condição de vivenciar o estado burguês e ao mesmo tempo criticar sua estrutura burocrática através da experiência musical do rock pôde e ainda pode me conduzir a outras formulações; a um local de transição, ponto de partida epistêmico pessoal.

Não é um esforço categórico de explicar o passado, mas um olhar panorâmico e crítico sobre posturas e manifestações poéticas destes tempos, com dois objetivos específicos: 1) encontrar na curiosidade de músico e compositor formas particulares de apreensão da realidade; 2) racionalizar a memória afetiva do poeta através de uma abordagem teórica dinâmica, que considere suas dimensões qualitativas a fim de levar em consideração tais dimensões no processo investigativo. A seguir apresento reflexões teóricas a fim de justificar estes objetivos. 


\section{Problematizar a opinião}

Eu poderia afirmar que essa leitura de minha experiência com o rock (um tanto íntima) é baseada em opinião, e que a teoria de Keightley serve muito bem para embasar de forma confortável tergiversações sobre meu passado, ao expressar com precisão memórias perceptivas. Para Bachelard (1971, p.165-167), a opinião é um dos primeiros obstáculos epistemológicos a superar na construção do conhecimento objetivo. Nunca partimos do zero, sempre de um conhecimento atual e/ou anterior que precisa ser posto à prova, mesmo quando assentado em conceitos de "fácil aceitação". Para o filósofo francês, mesmo as teorias precisam ser questionadas, criticadas pela consciência epistemológica. A história nunca é acabada, sempre retorna como problema, como necessidade de reconstrução.

Mesmo ao criticar o empirismo e o idealismo, Bachelard não descarta a necessidade de vivenciar uma experiência primeira como potência criadora. Seus escritos poéticos inspiram nesta direção. Superar a opinião e o senso comum imediato, não significa o abandono da primeiridade (como entende Peirce), estado de qualidade pura, de apreensão totalizante. Para Bachelard, a matéria tem uma realidade irredutível, por conta disso "A transformação do mundo em cosmos científico supõe, numa primeira etapa, a consciência imaginante do homem que busca compreender a matéria. É a abordagem poética do mundo, é o realismo ingênuo epistemológico" (CÉSAR, 1989, p.33).

O primeiro movimento do pesquisador é a consciência de sua matéria no mundo como dado objetivo, mas repleto de subjetividade; por isso, a noção de psicanálise do conhecimento ganha importância. A proposta de Bachelard é a alternância entre duas dimensões: a razão diurna e a imaginação noturna, a ciência e a poética como formas de vivenciar e interpretar a natureza. Em sua produção teórico-literária, ele apresenta uma forma de operar com essa "dicotomia" ao publicar livros identificados com uma ou outra percepção sobre o universo. Mas mesmo em reflexões teóricas aprofundadas, principalmente sobre o espírito científico, a linguagem poética aparece como espaço criativo, conforme ele mesmo acreditava, "Os eixos da poesia e da ciência são, inicialmente, opostos. Tudo que a filosofia pode esperar é tornar complementares a poesia e a ciência" (BACHELARD, 1938 apud CESAR, 1989, p.71). O ponto de encontro destas dimensões é o sujeito pesquisador, por isso que Cesar (1989, p.70) afirma:

A situação das ciências inspirada em Bachelard implica, portanto, uma antropologia que afirma determinada estrutura da consciência humana como suporte para as alternâncias entre a abordagem poética e científica do mundo. Esta alternância entre imaginação e razão não implica uma história irreversível; como só podemos conhecer cientificamente "aquilo, em torno do que sonhamos", há sempre um resíduo de poesia em toda abordagem científica. 
Não há como abandonar o instante poético, assim como não há como abandonar o corpo do pesquisador. E esse estar no mundo também põe em cheque a dicotomia entre sujeito cognoscente e objeto cognoscível, nas palavras de Feyerabend "A criação de uma coisa e a criação mais a compreensão plena de uma ideia correta da coisa são com muita frequência partes de um e o mesmo processo indivisivel e não podem ser separadas sem interromper esse processo" (2007, p.41, grifo do autor). Essas noções permitem aguçar o olhar para esse caso de pesquisa, onde enfrento a condição dúbia do sujeito pesquisador que retorna a seu próprio universo de memória. Nos termos da ciência positivista, onde o ponto de vista majoritário exige a separação entre sujeito e objeto, essa "presença" inviabilizaria uma perspectiva objetiva. No entanto, acredito que o pesquisador das ciências sociais enfrenta seu fazer com o corpo, ou seja "As perturbações ocorrem dentro do caráter do indivíduo e dentro do âmbito de suas relações imediatas com os outros; estão relacionadas com o seu eu e com as áreas limitadas da vida social, de que ele tem consciência direta e pessoal" (MILLS, 1982, p.14, grifo do autor).

O desafio é atuar como parte do fenômeno. Porém, diferentemente de uma fenomenologia impulsiva, é preciso criar condições operativas de ação, mapear os obstáculos a fim de transformá-los; criar uma compreensão da coisa, implica criar a coisa (FEYERABEND, 2007). Bachelard chama esse processo de fenomenotécnica: operar tecnicamente com todas as "peças" a fim de construir o "fenômeno" (PESSANHA, 1994, p.77). "A fenomenotécnica prolonga a fenomenologia. Um conceito torna-se científico na proporção em que se torna técnico, em que está acompanhado de uma técnica de realização” (BACHELARD, 2005, p.77).

Quais deslocamentos são possíveis quando o próprio fenômeno a ser construído é poético em si? Quais operações técnicas são possíveis a partir dessa dimensão poética no universo da pesquisa científica? Especificamente no caso do estudo sobre música, a partir de um olhar comunicacional e estético, como se articulariam tais racionalidades de construção do problema? Como este sujeito/pesquisador/músico/ poeta opera tecnicamente a fim de considerar tais dimensões e possibilidades sem esgotá-las, sem matá-las, sem torná-las caricatas, simplificadas, estéreis, ornamentais, decorativas? Qual a potencialidade que uma poética, de fato, exerceria sobre a fabricação de pesquisas empíricas no universo da pesquisa em comunicação na atualidade?

Entre o pesquisador e o poeta

A presença do pesquisador coloca um problema que não é novo. É tema de discussão sobre o campo e as dinâmicas de pertencimento/estranhamento na antropologia urbana e na etnografia contemporâneas (GEERTZ, 2009). No âmbito da comunicação como experiência estética, o "gesto" de Denílson Lopes é afirmar 
ciência como narrativa do comum, aproximação entre arte e vida cotidiana, menos interessada em "limites e transgressão", mas em "possibilidades". A experiência seria categoria provisória de espaço relacional: um "entre" identidade do sujeito pesquisador e mundo experimentado a compartilhar. A experiência "tenta atingir um certo ponto da vida que seja o mais próximo do 'invivível', que requer um máximo de intensidade e ao mesmo tempo de impossibilidade" (LOPES, 2006, p.120). Para o autor, é necessário experimentar o mundo a fim de refazer a "teoria pela narrativa", instável como um rastro, mas muito próxima a este narrador, vivida através dos sentidos e não da razão distanciada. Olhar o mundo desta perspectiva é assumir-se embriagado na sensualidade do observável, sem esboçar reação, exceto para refletir e balbuciar impressões carregadas de pessoalidade, imbricação, presença. Conhecimento estético que não é distanciado e categórico, nem analítico e frio, tampouco formal e totalizador. É sim uma apreensão assumidamente mergulhada na vivacidade e complexidade da cultura popular, nas suas formas de transcendência e permutabilidade cotidiana, no balaio estético dos carnavais do ser estar contemporâneo.

Essa proposta estabelece uma conversa instigante com a noção de instante poético, que aparece também como campo provisório de experimento, pois "Revela, ao mesmo tempo, no mesmo instante, a solidariedade da forma e da pessoa. Prova que a forma é uma pessoa e que a pessoa é uma forma. A poesia torna-se, assim, um instante da causa formal, um instante da potência pessoal" (BACHELARD, 1994, p.189). Neste lampejo, no qual o sujeito confunde-se com a forma, se estabelece o campo de embate pela constituição do sentido, entreposto da racionalidade e do estar no mundo. Por isso resume-se a um instante, não necessariamente de inspiração ou de vigor harmônico com a natureza transcendente, mas de dissolução, de indiferenciação entre quem sou e o que sinto. Longe de um mergulho impressionista, o movimento de recolocar-se a frente do processo narrativo, de reconduzir a ruptura na estrutura simbólica do texto, expande o instante no mundo material, o realiza enquanto cultura humana. O instante poético "apreende uma geralmente insuspeitada afinidade entre o ético e o poético, já que também 'toda moralidade é instantânea'. O poeta e o filósofo seriam, assim, dois artífices da instantaneidade, aqueles que fazem da solidão do instante a matéria-prima de suas construções” (PESSANHA, 1994, p.15).

A fragilidade potente do instante é um apelo à qualidade? A ética que emerge da poesia não é cumulativa, pois parece conduzir a processos mais íntimos, mesmo enquanto filosofia ou expressão identitária; apesar das metrópoles comunicacionais potencializarem os estímulos estéticos, as experiências do sensível, "a intensificação da vida dos nervos", como diria Simmel. Onde estaria o silêncio para nos reconduzir ao instante de assombro como matéria-prima? 


\section{A criação e a liberdade}

Ao levar em conta que a visão de Bachelard é antropocêntrica e que ao pesquisador cabe a tarefa de realizar as rupturas, de conciliar a convivência de dimensões, aparentemente, tão díspares quanto razão e imaginação poética, entendo que a liberdade textual e as possibilidades narrativas do conto científico dependem muito mais de seu processo construtivo, de suas amarras e concatenações, do que de rigidez estrutural. A psicanálise do conhecimento objetivo, portanto, assume papel fundamental.

No meu caso, a atitude de fé (metafísica?) na autenticidade é uma postura política do jovem músico, ainda latente. É um afeto? Uma opinião? Um obstáculo? Perguntas de fundo que ecoam no contínuo choque intersubjetivo do campo científico (WALLERSTEIN, 2007). Mas o autêntico é também o apelo de estar próximo ao sujeito ordinário, de escrever com fluência, complexidade, mas numa poética reinventada, um desejo de abertura a fim de vencer a timidez do desafio, o gaguejar da escrita. Como dissipar essa nuvem carregada entre o eu sou e o eu sei? Como dar vazão ao olhar atento do cientista na forma do linguajar fluente do contador de devaneios? Se o convite à fusão intelectual está posto, deve dar-se nos polos, nas extremidades. A fluência do poeta não é a mesma do pesquisador, mas pode inspirálo a libertar-se na direção de uma "Imaginação criadora que alimenta uma ciência que é, afinal, a estética da inteligência” (PESSANHA, 1994, p.11).

O desejo de abertura implica produzir perspectivas críticas aos modelos redutores. Podemos afirmar que duas condições sociais contribuíram (e ainda contribuem) para a hegemonia do paradigma positivista: a necessidade de "transformar o mundo" com base no conhecimento empírico quantificável e a racionalidade instrumental como forma estrutural organizativa. Para Furtado, tais condições só se realizaram a partir do desenvolvimento de uma mentalidade da acumulação, que produziu o clima receptivo à revolução científica: "a estruturação de um corpo de conhecimentos que se comporta como um subsistema autônomo de caráter cumulativo, que autodefine os seus métodos e campo de ação colocando-se fora da interferência de qualquer outra forma de conhecimento" (1983, p.201).

O estabelecimento da mentalidade acumulativa e da filosofia dos meios, onde o método científico torna-se forma unívoca de representar a realidade, explicá-la e fundamentar suas transformações, é um processo lento, realizado, pelo menos, ao longo dos últimos seis séculos; e está enraizado nas formas sociais contemporâneas. Como admite Furtado, "a dessacralização da natureza e a secularização da sociedade foram preparadas por práticas sociais que refletiam as exigências da acumulação" (FURTADO, 1983, p.200, grifo do autor).

A liberdade em tais condições assume o caráter de instrumento: "Quanto mais avança a acumulação, mais o sistema necessita de criatividade e mais a liberdade se subordina 
à lógica daquela, a qual exclui toda possibilidade de visão global” (Ibid., p.205) - o potencial aglutinador do autêntico no rock é um bom exemplo. Para Nietzsche, a racionalidade orientada ao progresso civilizatório conduz à desumanização. Submetido às formas morais, o homem precisa encontrar vontade de poder, capacidade criadora de autotransformar-se para além, inclusive, dos métodos socialmente definidores do que seria a própria noção compartilhada de humanidade. Para encontrar qualidades comunicacionais diversas, é preciso olhares epistêmico-metodológicos inventivos. Livres?

Enquanto aprendizado novo, a liberdade anda ao lado dos mecanismos de fuga, da automatização, da alienação. Sua autoafirmação pode ser a raiz de sua negação. Operar nesse limite é caminhar na fronteira, pois um conhecimento científico absolutamente aberto, livre, despreocupado, perde seu sentido, corre o risco de transformar-se em autismo ou puro subjetivismo. $\mathrm{Na}$ ciência há liberdade vigiada e institucionalizada. Possível? A própria noção de liberdade é uma armadilha conceitual, não um estado acabado ou uma condição a conquistar, mas busca incessante.

No caso das sociedades contemporâneas, uma busca tanto interior quanto exterior. A ruptura do sujeito com as amarras externas não significa liberdade, como afirma Fromm (1986, p.136) “a evolução do pensamento moderno, desde o protestantismo até a filosofia de Kant, pode ser caracterizada como a substituição da autoridade externa por outra interiorizada". A "vitória da liberdade" em nosso projeto atual é quase sinônimo do estabelecimento de autoridades anônimas: a ciência, a saúde mental, a normalidade, a opinião pública etc.

Autoridade anônima é mais eficaz do que a ostensiva, porquanto nunca se desconfia que haja uma ordem que por hipótese se deve obedecer. Na autoridade externa está claro que há uma ordem e quem a dá; pode-se lutar contra a autoridade, e, nesta luta, desenvolvem-se a independência e a coragem moral (FROMM, 1986, p.137).

A psicanálise é importante para o pesquisador, pois é uma forma de manter abertos canais reflexivos sobre as condições de produção de pensamento, busca rigorosa a fim de tornar claros processos de manifestação da consciência. Pois a coerção institucional exerce aí sua castração: "A racionalização não é um instrumento de penetração da realidade, mas uma tentativa a posteriori de harmonizar os desejos da própria pessoa com a realidade existente" (FROMM, 1986 p.157). Para Fromm, o pensamento é sempre original, sempre tenta explicar um fenômeno vivenciado, porém traz consigo os medos, as fugas, as angústias internalizadas no processo de individuação do sujeito (advindos dos traumas, das opressões, das fugas mentais), "O ponto decisivo não é o que é pensado, porém como é pensado" (FROMM, 1986, p.157, grifo do autor).

A história pode ser narrada como um processo de lutas externas contra as coações espirituais da religião, os poderes absolutistas dos estados, enfim, a busca pela 
emancipação política, o estabelecimento de uma liberdade de. O fenômeno do rock fornece uma analogia interessante: a ruptura infantil no primeiro momento, travestida de espírito ao mesmo tempo moderno e romântico, como bem aponta Keightley. Mas o que pode fazer uma música liberta de suas condições normativas e formais? Como ela transcende a liberdade de, até uma liberdade para? A polêmica interna e a autenticidade são as respostas que Keightley apresenta.

Acreditar em tal liberdade no espectro musical nos levaria a ignorar as condições de castração institucional vivenciadas na modernidade. As reações de nosso espírito aos processos violentos de recrudescimento do capitalismo global de mercado que nos levam a internalizar as normatizações sociais ao ponto de assumi-las como nossas.

Tanto a ciência, quanto a música (em específico o rock) lidam com o imperativo do espírito renovador, com a juventude das ideias, com a necessidade da construção de pontes entre o homem e sua consciência. Embora submetidas às condições materiais do capitalismo, os saberes da ciência e da arte são formas de acesso e de movimento conscientes. Neste sentido, o próprio ato de observar torna-se técnico, pois é essa capacidade que conduz a criação e ao processo científico (e artístico). Tendo em vista os dois postulados que sustentam a ciência: a existência objetiva e a cognoscibilidade do universo (GORTARI, 1979, p. 30-31).

A observação traz sempre a "tensão psíquica" advinda do próprio enfrentamento dos fenômenos, potencial inerente ao homem enquanto ser "consciente-sensívelcultural", que cria através da manipulação das formas materiais e imateriais disponíveis (tais como as abstrações e as memórias, por exemplo) arranjadas intencionalmente. Mesmo organizados em níveis pré-conscientes, estes arranjos geram "constelações associativas". Para Ostrower (2008, p.20), “Apesar de espontâneo, há mais do que coincidência no associar. Há coerência”. Então, a criação, sobretudo quando articulada à investigação científica, precisa ser questionada, pois sua tendência é uma articulação coerente, uma forma organizativa sedutora e significante, mas que nem sempre conduzirá ao conhecimento objetivo. A tarefa do criador também é autorreflexiva.

Essa dinâmica humana talvez explique como sobrevivemos e encontramos a felicidade, apesar das autocastrações de nossa autoridade interna. A ressignificação das formas, os deslocamentos dos usos (como afirma Certeau), são resistências humanas adquiridas no percurso evolutivo da espécie, sempre em estreito contato com o entorno cultural. Mas essa habilidade psicológica e "fenômeno midiático de exteriorização dos processos mentais" implica no que Verón, a partir de sua visão semioantropológica da midiatização, chama de tríplice diferença:

Em termos peircianos, mais uma vez, sua primeiridade consiste na autonomia dos emissores e receptores dos signos materializados, como resultado da exteriorização; sua secundidade é a subsequente persistência no tempo dos signos materializados: alterações de escalas de espaço e tempo se tornam inevitáveis, e a narrativa justificada; sua terceiridade é o corpo das normas sociais definindo as formas de acesso aos signos já autônomos e persistentes (2014, p.15). 
Nessa perspectiva, a liberdade criativa adquire um traçado problemático a percorrer, inicialmente o esforço da materialização desse signo imbricado na experiência cultural qualitativa do sujeito (primeira ou segunda), donde deriva a habilidade linguística para narrar a secundidade, a possibilidade de persistência temporal inserida no discurso científico e sua normatização. Não se trata de mecanizar etapas (como se pudéssemos dissecar o processo semiótico), mas o que Verón sugere é a necessidade de formular politicamente a produção simbólica, pois a própria consistência fluída e pré-consciente destes atravessamentos desloca a sensibilidade, obnubila a visão, gera conflitos mentais. Às vezes confundimos o fazer científico com reproduzir o estabelecido, com seguir a normatização, já que "a relação de identidade entre Saber e Poder nasceu com a ciência moderna” (JAPIASSU, 1999, p. 300). Talvez, uma abordagem crítica da forma parece necessária, pois guarda um aspecto de vigília (o devaneio de Bachelard), de rompimento com a coerência naturalizada das associações mentais, com a ingerência das memórias como "conformismo de autômatos" (FROMM, 1986, p.150). Neste ponto, é válida a afirmação do homem como ser cultural criador de signos, e da lógica dialética como uma forma de compreender o processo elucidativo e criativo da ciência. Como afirma Sartre: "O homem constrói signos porque ele é significante em sua própria realidade, e é significante porque é superação dialética de tudo o que é simplesmente dado. O que chamamos liberdade é a irredutibilidade da ordem cultural à ordem natural” (1973, p.184).

Na escrita das ciências sociais precisamos admitir o "ônus da autoria" (GEERTZ, 2009, p.182) como parte da busca pela objetividade. Criação, imaginação e invenção, portanto, não são sinônimos de distorção, mas da necessidade operacional, da práxis do pesquisador. A discussão aqui proposta é sobre as condições de autoria e quando se inicia esse processo. Por exemplo, quando volto o olhar para estes momentos anteriores de minha vida, até que ponto encontro autonomia para construir essa narrativa desde a ruptura epistemológica atual? Há como abrir mão das experiências anteriores e seus significados presentes? Essa visão sobre o passado é do pesquisador ou do poeta? Como lidar com essa dupla escritura?

A tentativa é problematizar o processo de exteriorização dos signos, a elaboração formal e interna da produção autoral. Não de uma forma exaustiva no empenho semiótico, com foco nos processos de significação, mas com o objetivo de questionar a naturalização da coerência formal do texto, a coerência indutora da linguagem escolhida (não apenas das palavras limitadas, mas dos próprios materiais). Se a liberdade é um valor aceito no fazer científico, desde que submetida a intersubjetividade da polêmica interna, a proposta desta pesquisa é experimentá-la; no sentido de torná-la técnica, a fim de ensaiar uma possibilidade de transcender a liberdade de a fim de construir uma liberdade para.

Ao levar em conta a metodologia como processualidade reflexiva, acredito que minhas habilidades experimentais e lúdicas com a poesia e com a composição musical (ambas desenvolvidas de forma autodidata) comparecem neste início de investigação 
como procedimentos organizativos, como mediações entre pesquisador/objeto. São linguagens com as quais elaborei os movimentos de rock e juventude entre os anos 1995 e 2005, enquanto um intérprete deste tempo. Atualmente, ao reler ou reinterpretar algumas destas poesias e canções, tenho a sensação de que exerço certa liberdade provisória e tentativa. Quiçá autêntica, pois livre dos compromissos formais do mercado, das cenas musicais de outrora, dos parâmetros de qualidade impostos pelos sistemas sociais aos quais me submeti quando investi com todas as forças na carreira artística. Hoje, são práticas cotidianas, íntimas, noturnas.

Pretendo integrar essas práticas como dimensão metodológica da investigação. Inicialmente, como um esforço empírico interior, como uma experiência psicanalítica de qualidades mais etéreas, mais abertas, provocadoras e invocadoras. Materialidades que podem iluminar outras zonas e procedimentos, tornar nítidas fronteiras e percursos mais rígidos. Essa invenção formal aparece no marco da observação participante, como um diário de campo, como uma estrutura narrativa experimental a ser observada, não necessariamente incluída no texto final, na proposta redacional, mas como um jogo auxiliar de conformações significativas. Práticas afetivas cotidianas com significados potentes e representativos em relação ao objeto estudado (de natureza semelhante).

\section{Um pesquisador em construç̃o}

Amparado nas perspectivas narradas acima, constituo através dessa investigação minha identidade de pesquisador (e de poeta). Parte deste experimento, que nas palavras de Elí de Gortari “no es objeto de sí mismo sino que son los processos de la naturaleza y de la sociedad, en su intrincada conexión y en su acción recíproca universal" (1979, p.37), depende de minha imersão no universo sociocultural contemporâneo. A opção pelas linguagens artísticas não é um aforismo, mas um percurso integrado as perspectivas teóricas dos estudos culturais e do grupo de pesquisa Processocom ${ }^{3}$, coletivos que tem contribuições significativas para o avanço da ciência e da sociedade em termos de visão crítica e transformação social.

Para finalizar, trago um trecho da Poética da obra aberta, de Umberto Eco, que expressa com clareza minha tentativa de teorização neste texto, cujo objetivo foi tatear lugares de encontro entre arte e ciência, como uma estratégia de construção do saber.

Com efeito, é sempre arriscado sustentar que a metáfora ou o símbolo poético, a realidade sonora ou a forma plástica constituem instrumentos de conhecimento do real mais profundos do que os instrumentos proporcionados pela lógica. $O$ conhecimento do mundo tem na ciência seu canal autorizado, e toda aspiração do artista à vidência, ainda que poeticamente produtiva, contém sempre 
algo de equívoco. A arte, mais do que conhecer o mundo, produr. complementos do mundo, formas autônomas que se acrescentam às existentes, exibindo leis próprias e vida pessoal. Entretanto, toda forma artística pode perfeitamente ser encarada, se não como substituto do conhecimento científico, como metáfora epistemológica: isso significa que, em cada século, o modo pelo qual as formas da arte se estruturam reflete - à guisa de similitude, de metaforização, resolução, justamente, do conceito em figura - o modo pelo qual a ciência ou, seja como for, a cultura da época veem a realidade. (ECO, 2012. p.54-55, grifo do autor).

A musicalidade autodidata é a forma pela qual experimento o mundo, atuo e produzo sentido. Não de forma isolada, mas enquanto membro de uma cultura específica, situada no tempo e no espaço, que realiza materialmente suas expressões através da criatividade e de algum rigor reinventado. Estas são as metáforas com as quais percebo o mundo. A proposta de estudar o instante poético como apreensão científica não é um ato transgressor, tampouco a esperança de ser autêntico por teimosia. É a assunção de meus processos internos como fontes, como forças produtivas, como etapas importantes a serem questionadas e elaboradas neste traçado sinuoso da construção dos fenômenos. São as técnicas disponíveis, as melhores que encontro no momento, acho prudente apresentá-las. 
Referências

BACHELARD, Gaston. A epistemologia. Lisboa: Edições 70, 1971.

BACHELARD, Gaston. O direito de sonbar. 4.ed. Rio de Janeiro: Bertrand Brasil, 1994.

BOURDIEU, Pierre. et al. Ofício de Sociólogo. 5.ed. São Paulo: Editora Vozes, 2004. 328p.

CERTEAU, Michel de. A invenção do cotidiano. v. 1. Artes de fazer. 2. ed. Petrópolis: Vozes, 1994.

CESAR, Constança Marcondes. Bachelard: ciência e poesia. São Paulo: Edições Paulinas, 1989.

ECO, Umberto. Obra aberta: forma e indeterminação nas poéticas contemporâneas. 9. ed. São Paulo: Perspectiva, 2012.

FEYERABEND, Paul K. Contra o método. São Paulo: UNESP, 2007.

FROMM, Erich. O medo à liberdade. 14. ed. Rio de Janeiro: Guanabara, 1986.

FURTADO, Celso. Da economia para a filosofia. In: OLIVEIRA, Francisco de. (org.). Celso Furtado: economia. (Coleção Grandes Cientistas Sociais, 33). São Paulo: Ática, 1983. p. 197-218.

GEERTZ, Clifford. Obras e vidas. O antropólogo como autor. 3. ed. Rio de Janeiro: Editora UFRJ, 2009.

GORTARI, Eli de. Introducción a la lógica dialéctica. México: Fondo de cultura econômica, 1979.

JAPIASSU, Hilton. As paixões da ciência. 2. ed. São Paulo: Letras y letras, 1999.

JAPIASSU, Hilton. Introdução ao pensamento epistemológico. 2. ed. Rio de Janeiro: Francisco Alves, 1977.

KEIGHTLEY, Keir. Reconsiderar el rock. In: FRITH, Simon; STRAW, Will; STREET, John (orgs.). La Otra História del Rock. Aspectos clave del desarollo de la música popular: desde las nuevas tecnologias hasta la política y la globalización. Barcelona - ESP: Ma Non Troppo, Ediciones Robinbook, 2006. p. 155-194.

LOPES, Denílson. Da estética da comunicação a uma poética do cotidiano. In: GUIMARÃES, César, LEAL, Bruno Souza, MENDONÇA, Carlos Camargos. (orgs.). Comunicação e experiência estética. Belo Horizonte: Editora UFMG, 2006. p. 117-150.

MARTEL, Frédéric. Mainstream. Rio de Janeiro: Civilização Brasileira, 2012.

MILLS, C. Wright. A imaginação sociológica. Rio de Janeiro: Jorge Zahar, 1982.

MORIN, Edgar. Cultura de massas no século XX. Vol. 1: Neurose. 3. ed. Rio de Janeiro: Forense Universitária, 2011.

MORIN, Edgar. Cultura de massas no século XX. Vol. 2: Necrose. 3. ed. Rio de Janeiro: Forense Universitária, 2009. 
OSTROWER, Fayga. Criatividade e processos de criação. 21. ed. Petrópolis/RJ: Vozes, 2008.

PESSANHA, José Américo Motta. Apresentação. In: BACHELARD, Gaston. O direito de sonhar. 4.ed. Rio de Janeiro: Bertrand Brasil, 1994.

SARTRE, Jean-Paul. Questão de método. Tradução de Bento Prado Júnior. São Paulo: Abril Cultural, 1973. (Os Pensadores, 45).

VERÓN, Eliseo. Teoria da midiatização: uma perspectiva semioantropológica e algumas de suas consequências. In: Revista Matrizes. v. 8, n. 1, jan-jun, 2014. Revista do programa de Pós-Graduação em Ciências da Comunicação da Universidade de São Paulo, USP. São Paulo, Brasil.

WALLERSTEIN, Immanuel. et. al. (orgs.). Abrir las ciencias sociales. Informe de la Comisión Gulbekian para la reestruturación de las ciencias sociales. 10. ed. Buenos Aires: Siglo XXI editores, 2007.

Notas

1 O independente se relaciona aqui ao universo da "contracultura, da subcultura, dos nichos", como inverso ao mainstream, como "um produto ou serviço cultural que visa, exclusivamente, um público amplo" (MARTEL, 2012, p.20). Não é o objetivo discutir essa categoria aqui, cito essa noção simplificada apenas para a definição.

2 Por conta das políticas de privacidade da autoria não cito aqui as experiências profissionais de músico, mas na versão final, pretendo fazê-lo.

3 Informações sobre o grupo Processocom diponíveis em: http://processocom. org/ 